\title{
On the issue of international legal regulation of ensuring environmental safety in water transport in the Black Sea
}

\author{
Veronika Yurievna Lantseva* \\ Admiral Ushakov Maritime State University, Novorossiysk, Russia
}

\begin{abstract}
This article studies the mechanism of protection of the Black Sea marine environment ensuring environmental safety in water transport in its water area, which was normatively consolidated in the 1992 Convention on the Protection of the Black Sea from Pollution. The article studies and describes the international and regional experience of regulating public relations arising from the provision of environmental safety, as well as proposals for improving international law in this area. The article presents the major research outcomes on the main measures aimed to introduce amendments to the current international law on regulation of public relations arising in the field of ensuring environmental safety in water transport in the Black Sea. Based on the analysis of the current international regional agreement in the area under consideration, the author has proposed some recommendations for its further development, and also highlighted the main areas to be regulated taking into account the need to conduct research in order to create the necessary rules and regulations that can ensure environmental safety in the operation of sea vessels. In order to improve the ecological situation in the Black Sea water area, it is necessary to amend the Convention on the Protection of the Black Sea against Pollution by introducing a number of special measures proposed in the article.
\end{abstract}

\section{Introduction}

The problem of pollution of the marine environment and its threat is characteristic of enclosed and semi-enclosed seas surrounded by several states and having a narrow outlet to the ocean. The Black Sea falls within this category. The Black Sea area is an area with a high anthropogenic impact; it has been densely populated by humans since ancient times.

Research in the field of ensuring the ecological safety of the Black Sea continues to be relevant for many decades. This happens due to serious disturbances in the natural system resulting from the anthropogenic factor including the active development of water transport [1]. The diversity and beauty of landscapes represent the most important natural heritage for our society and future generations. Under conditions of serious anthropogenic impact and intensive use of natural resources, the resources of the sea are depleted and, accordingly, the ecological state of water bodies needs constant monitoring and protection.

Oil pollution is one of the most serious types of pollution. Over the past fifty years, its level has increased significantly and has a constant, stable character due to the high traffic load in the Black Sea basin.

\section{Problem setting}

Humanity was seriously concerned about the legal regulation of the protection of the marine environment in the second half of the $20^{\text {th }}$ century. The 1982 UN Convention on the Law of the Sea is the key international agreement that establishes the principles of preventing or minimizing the consequences of all types of pollution of the marine environment.

For a long time, the ecological situation in the Black Sea did not cause serious concerns; it was a disposal site, was used for fishing and shipping without reasonable restrictions and it was believed that the marine environment was able to withstand such pressure. However, after the 60 s of the last century, the situation changed, environmental indicators began to deteriorate sharply, which caused serious unrest on the part of the world community, especially the coastal states.

The Black Sea is highly susceptible to oil pollution that enters the water masses as a result of developed shipping in this area. Meanwhile, the ability of the Black Sea basin to self-purify is gradually decreasing due to low rates of construction of water protection facilities, ineffective work of the existing ones, and emergency discharges. Despite the fact that accidental spills in the Black Sea are usually small, the construction of new storage facilities for oil products increases the danger. Most of all, the environmental situation is deteriorating as 
a result of an increase in the transportation of environmentally hazardous cargo, crude oil, oil products [2].

The above can lead to conclusion that the Black Sea water area and its coast are experiencing a strong negative anthropogenic impact cased particularly by waste from ships. The global reasons for the unsatisfactory ecological situation in the region are the lack of a systematic and unified approach to the creation of local treatment facilities, the indifference of the coastal states to the process of creating an international program to improve the ecological state of the Black Sea. The countries need to carry out joint environmental protection measures in order to improve the quality of natural and waste waters by improving methods of their treatment considering the existing environmental problems [3]. When carrying out activities in the Black Sea, countries are obliged to comply with the permissible discharge standards thereby helping to reduce the risk of additional pollution and increase the level of the existing one. The states need to strictly adhere to the norms established by the Bucharest Convention and adapt national environmental legislation to its provisions.

Over the past 20 years, violations of the Convention for the Protection of the Black Sea against Pollution have occurred more than once. In particular, a strong storm in the Kerch Strait in 2007 caused 4 ships to sink including a tanker. As a result of the accident, 1.3 thousand tons of fuel oil spilled into the water. On the fact of this incident, a criminal case was initiated under Art. 263 of the Criminal Code of the Russian Federation "Violation of Traffic Safety Rules and the Operation of Railway, Air or Water Transport" and Art. 252 of the Criminal Code of the Russian Federation "Pollution of the Marine Environment".

On November 20, 2020, the judge of the Arbitration Court of the Krasnodar Territory Natalya Khakhaleva, within the framework of the consideration of case No. A32-15997/2020 made a decision to satisfy the claim of the Chernomor-Azov Maritime Administration of Rosprirodnadzor against AO "Zernovoy Terminal "KSK" to recover compensation for damage caused to the Black Sea as a result of the pollution of the Tsemesskaya Bay water area produced by the company. The court ordered to recover from the company the damage caused to the water body in the amount of 856 thousand rubles.

On August 6, 2019, during a road inspection of the water area of the seaport of Novorossiysk, the Chernomor-Azov Maritime Administration of Rosprirodnadzor revealed an offense in the Tsemesskaya Bay. A section of the water area operated by AO "Zernovoy Terminal "KSK" was contaminated with a large amount of floating household waste (boards, branches, plastic and glass bottles, bags, etc.). The waste was also accumulated in the underwater space. In addition, the water area was clogged with grain dust and husks as a result of loading grain onto the vessel "ON LONG BAY". The company purposefully did not purify the water surface. The Rosprirodnadzor department concluded that these facts were characteristic of an administrative offense qualified by the article of the Code of Administrative Offenses of the Russian Federation (violation of water use rules). The damage caused to the water body according to the calculations of the Office amounted to 856,207 rubles. The company refused to settle the issue and comply with the claims, as a result of which the Office applied to the arbitration court with a claim for damages. The court found that the terminal violated the requirements provided for in part 2 of article 37 of the Federal Law "On internal sea waters, the territorial sea and the contiguous zone of the Russian Federation", according to which the discharge of pollutants in the internal sea waters and in the territorial sea is prohibited, which complies with the provisions of the Bucharest Convention. The company also violated the rules established by Art. 176 of the "Technical Regulations on the Safety of Maritime Transport Facilities", according to which infrastructure facilities of maritime transport must be provided with technical means and specialized vessels in sufficient quantity to clean up the territory and water area from garbage, oil products and other harmful substances, which complies with the provisions of the Convention. The company tried to prove its innocence in court. However, on November 20, 2020, the Arbitration Court of the Krasnodar Territory satisfied the claim, and the terminal was brought to justice. AO "Zernovoy Terminal "KSK" is one of the operators of sea terminals of the seaport of Novorossiysk in accordance with the order of Rosmorrechflot. The company was given a section of the port water area for loading and unloading operations. In this regard, the court ordered the company to have its own technical means designed to clean the water area from garbage, oil products and other harmful substances. At the time of the offense, the company had an agreement to carry out such activities with AO "NCSP Flot" but did not take all measures to prevent pollution of the Black Sea water area, which it uses as the operator of the sea terminal of the port of Novorossiysk. In addition to the fact that the polluter was held liable for actions that caused harm to the Black Sea basin, this judicial precedent should further influence the situation with the maintenance of berthing facilities of various companies.

\section{Materials and methods}

The main international legal norms for the protection of the marine environment, which are universal and global, primarily include the international legal norms specified in the 1982 UN Convention on the Law of the Sea. Adopted on February 10, 1982 in Montego Bay, Jamaica, the Convention has become a truly fundamental document for the regulation of the law of the sea. Until the 80s of the last century, the law of the sea was a set of disparate international legal and regional norms united only by a common legal object being the marine environment. The Convention made a powerful breakthrough in the codification of the law of the sea combining the basic concepts and provisions binding on most countries in the world. Today it comprises 170 states. Russia ratified the legal act on February 26, 1997. In addition to the fact that the Convention enshrines the 
most important definitions at the international level and establishes a clear division of the sea space, the treaty contains information devoted to the protection of the marine environment. Thus, Part 12 of the Convention contains 11 sections and 46 articles establishing the main provisions for the protection of the marine environment for all states that have ratified the document. According to these provisions, all states are obliged to maintain close cooperation on all issues of preserving the marine environment: prevention of pollution and damage, control over environmental safety, constant monitoring of the state of the environment, the use of the latest technologies in environmental protection, litigation and compensation for damage caused. At the same time, the participants have a duty to provide assistance to developing countries, and those that cannot adequately ensure the preservation of the fragile biosphere. States must immediately inform each other on all critical issues related to the environmental situation of the sovereign regions of the seas and oceans. Prevention of the marine environment pollution, which can come from absolutely any source (land, ships, the atmosphere, activities in the development of the seabed, disposal sites at the bottom) is the main task of the parties to the Convention. Moreover, states agree to transform their domestic legislation regulating the protection of the marine biosphere in accordance with the provisions of this agreement. To some extent, the Convention copies the already existing international legal acts on the protection of the marine environment at that time, and to some extent supplements and expands them. All subsequent Conventions adopted with the aim to protect the marine environment borrowed or copied the provisions of the above document in one way or another.

However, before the 1982 Convention appeared, a number of international legal acts were adopted to regulate the protection of the marine biosphere. One of the first acts was the 1969 Convention on Intervention on the High Seas in Cases of Oil Pollution Accidents.

The question of securing the right of countries to intervene in neutral waters in a contractual manner was raised after the accident of the tanker "TorriCanyon" in 1967, which occurred in the English Channel. Then the nature of Great Britain suffered colossal damage.

Considering the principle of freedom of navigation on the high seas and the inadmissibility of its arbitrary violation, the right of coastal countries to intervene was significantly limited by Article 1 of the 1969 Convention, according to which intervention was carried out only in serious and real threatening situations for the coast and the danger of coastal waters pollution.

The further international treaties in this area were the 1972 Convention on the Prevention of Marine Pollution by Dumping Wastes and Other Matter (dumping in the Convention means the deliberate disposal of waste from ships at sea or the burial of ships at sea) and the International Convention on the Prevention of Pollution from Ships (regulates issues dumping waste into the sea, which is the result of the correct maintenance of water transport). The last treaty specifies two annexes, which contain lists of completely banned and restrictedly prohibited substances for dumping, as well as a list of substances requiring authorization when they are dumped, which is carried out in accordance with the established procedure and in agreement with the states responsible for permission granting. The convention came into operation three years after its adoption in 1975. In 1996, there was adopted a Protocol significantly supplementing it, and ultimately replacing it. In accordance with the provisions of the protocol, dumping of any waste and substances is completely prohibited, with the exception of special categories of waste. The protocol prohibits burning waste and materials at sea and exporting it to other countries for incineration at sea. However, there is an exception to the rules in cases where such activity is necessary to ensure the safety of human life or ships in the event of force majeure caused by bad weather, or in any case when there is a danger to human life or a real threat to the ship. The protocol came into force only 10 years later, in 2006.

In addition to international conventions created to protect the marine environment from pollution, there are a number of regional agreements and treaties that govern this area of law. Thus, a number of agreements were adopted to ensure the environmental safety of the Baltic, Red, Mediterranean, Caribbean and other seas. One of the last agreements was the Convention for the Protection of the Black Sea from Pollution (Bucharest, Romania) adopted in 1992.

This document aims to protect the water body from negative anthropogenic impact. It contains a detailed description of the legal framework for cooperation between the Black Sea states in order to save, preserve and protect living resources from negative impacts, as well as to correct existing environmental problems. The convention was signed by Russia, Bulgaria, Turkey, Greece, Ukraine, Georgia and Romania.

\section{Results and discussion}

Currently, there are many international legal acts regulating the protection of the marine environment despite the fact that the world community began to regulate legal relations in this area only half a century ago. The sphere of legal regulation of ensuring environmental safety in water transport today has a high level of development. It is important to note the special role of regional agreements since they provide an opportunity for countries to solve the problem of marine pollution in more detail taking into account the characteristics of each individual region. However, it is obvious that in the last twenty years the emphasis in the development of legal regulation of the protection of the environment and the marine environment has been placed not on the number of various international and regional treaties but on the quality of such documents. The existing acts are polished and perfected by numerous protocols and annexes, as well as more and more often questions about violation of certain norms for the protection of nature by some countries are brought up on the agenda. However, to improve the performance of the regulatory mechanism, a lot of effort is still to be made.

The preamble to the Bucharest Convention contains 
the basic principles established by the contracting parties. Thus, first of all, the parties aim to achieve progress in protecting the marine environment of the Black Sea and preserving its living resources. The social and economic significance of the Black Sea as well as its medicinal properties are of particular value to the members of the agreement. Most likely, this is due to the favorable climatic conditions of the Black Sea region, which determine its status as a resort region. The principles of international law governing the protection and preservation of the marine environment come to the fore in this document. However, the principle of cooperation is also important for the parties, and cooperation should be carried out in the field of science and technology [4; 5].

The parties to the agreement considered it necessary to note that the provisions of the document were consistent with the provisions of the 1972 Convention on the Prevention of Marine Pollution by Dumping of Wastes and Other Matter as amended; The International Convention for the Prevention of Pollution from Ships, 1973 as amended by the 1978 Protocol; The 1989 Convention on the Control of Transboundary Movements of Hazardous Wastes and Their Disposal; International Convention on Oil Pollution Preparedness, Control and Cooperation, 1990.

The Bucharest Convention identifies an important problem being as follows: the existing international agreements do not cover all aspects concerning pollution of the marine environment of the Black Sea originating from third countries. This implies another goal, specifically, the need for close cooperation with relevant international organizations on the basis of a coordinated regional approach aimed to protect and improve marine environment of the Black Sea.

The term "Harmful Substance" in the Bucharest Convention combines the two terms "Harmful Substance" and "Hazardous Substance". Article 6 of the Bucharest Convention states that the parties are obliged to cooperate in combating pollution caused by harmful substances, and refers to Annex 1 of the Convention, which contains a list of hazardous substances and materials, and the list of poisonous substances is contained in Annex 2. The Protocol on Cooperation in Combating Pollution of the Marine Environment of the Black Sea by Oil and Other Harmful Substances in Emergency Situations also specifies the methods of combating pollution caused by harmful substances. The parties are obliged to develop and improve plans to reduce pollution of the marine environment with harmful substances, inform each other about pollution incidents, immediately identify violations and exercise constant control over their ships $[6 ; 7 ; 8]$. In the event of an accident, any state party to the convention is obliged to immediately transmit a report about it to the state that may be affected by the consequences of pollution, as well as the Commission for the Protection of the Black Sea.

The Bucharest Convention does not contain the term "incineration", and as a result does not contain a ban on this activity in the Black Sea region. Such a gap is surprising because oil spills in the Black Sea occur quite often [9; 10]. Moreover, as noted during the study, an important problem of the Black Sea is hydrogen sulfide, which has flammable properties. Official research on the problem of combustion in the Black Sea has not been carried out. However, taking into account the properties of the Black Sea basin, such research is advisable [11].

Dumping in the Black Sea is carried out in accordance with Article 10 of the Bucharest Convention. The article does not contain a ban on dumping but only explains the need to prevent pollution caused by such activities. However, paragraph 2 of the above article prohibits dumping in the Black Sea region to individuals and legal entities of non-Black Sea states. This Convention has a Protocol for the Protection of the Marine Environment of the Black Sea against Pollution Caused by Dumping, which prohibits the disposal in the Black Sea of wastes containing the substances listed in Annexes 1 and 2 . Article 7 of the Protocol lays down rules for the accounting of dumped waste by the competent authorities designated by the parties. Despite the above provisions of the Convention, the question arises about the possibility of dumping in the Black Sea in principle. Official research on this topic has not been carried out, and it is not possible to fully assess the consequences of dumping in the Black Sea basin. It is fair to say that dumping at sea was infrequent. However, the issue of interaction of hydrogen sulfide with dumped waste is likely to be raised in the near future. It seems appropriate to recommend to the parties to the Convention a full-fledged consideration of the issue of a complete ban on dumping in the Black Sea region.

Study findings revealed the need to specify sanctions in relation to acts that contradict the requirements established by the Convention in an additional Protocol or Annex of the Convention. The lack of a welldeveloped mechanism for the appointment and application of penalties does not allow countries to fully feel the responsibility for committing crimes against the ecology of the marine environment.

An analysis of the ecological state of the Black Sea showed that national norms establishing responsibility for illegal acts are not enough since there is no full awareness of the scale of the growing number of problems even at the state level not to mention individuals and legal entities. Some Black Sea countries do not pay due attention to the norms established by the agreement and do not set an important national task to ensure environmental safety in water transport.

In addition, to improve the ecological situation in the Black Sea water area, it is necessary to amend the Convention on the Protection of the Black Sea from Pollution specifying a number of special measures and financial costs in the prescribed manner by the participating States. In our opinion, the measures should consist in the following: development of a concept of nature management that is unique for the Black Sea region; tightening control over harmful emissions from water transport; a large-scale purchase of equipment for clearing the coastal zone from pollution (moreover, the states with more developed economies can provide financial support to poorer neighbors in the purchase of 
the necessary equipment); stimulating the use of environmentally friendly fuel by ships; the introduction of strict penalties for pollution of the marine environment; encouraging regional enterprises to use environmentally friendly equipment.

\section{Conclusion}

During the existence of the Bucharest Convention and the Commission created within its framework, unfortunately, the ecological situation has not changed for the better. Pollution in the Black Sea region has only increased over 30 years while it would not be entirely correct to say that the commissions have not taken any action. Perhaps, previously adopted norms are simply not able to regulate the constantly increasing level of pollution and require revision or additions. Moreover, the provisions of the Bucharest Convention are not sufficiently specific, which allows states to circumvent them being unafraid of significant sanctions from the international community.

At present, attempts to eliminate a number of environmental problems both at the regional and national levels are being made rather weakly. Sadly, countries value economic well-being higher than maintaining a healthy marine environment. However, in order to eliminate the imperfections of the provisions of the conventions, the protocols substantially supplementing, developing and concretizing the norms established by the agreements were subsequently adopted.

In this regard, we consider it advisable to toughen the sanctions rules applied to states that violate regional conventions. Specification is also necessary for the coastal states not to use existing regional norms for developing national norms contradicting provisions of the conventions.

\section{References}

1. O.N. Baburina, M.V. Botnaruyk, S.I. Kondratiev, Intellectual problems of implementing road map for development of russian marine industry (MariNet) in the framework of National technological initiative, Marine intellectual technologies, 3(41), vol. 1, 190198 (2018)
2. V.V. Zaslonov, A.A. Golovina, A.N. Popov, Creating a Crewless Ship in the Framework of the Technological Paradigm of the Russian Federation, Lecture Notes in Networks and Systems, 1(115), 468-474 (2020)

3. S.K. Abrahamyan, K.V. Golubkina, Interdepartamental cooperation as regards water transport in Russian Federation, Marine intellectual technologies, 1(43), 2, 82-85 (2019)

4. A.L. Boran-Keshishyan, S.I. Kondratiev, A.N. Tomilin, The development of bank of test tasks for the state final examination of graduates from maritime educational institutions, Marine intellectual technologies, 1(43), 2, 149-156 (2019)

5. Seongwan Kim, Hyeonmin Jeon, Jongsu Kim, Trend analysis of domestic and international regulations for electric propulsion system, Journal of International Maritime Safety, Environmental Affairs, and Shipping, 4(3), 113-121 (2020)

6. A.V. Agafonov, Legal and economic instruments for the regulation of environmental safety in water transport in the Russian Federation, Natural and humanitarian research, 15(1), 4-18 (2017)

7. A.A. Ivanova, A.V. Polishchuk, Organizational and legal regulation of international cooperation in the field of safety and protection of the marine environment, Ocean Management, 1(10), 13-18 (2021)

8. A.S. Borisova, International legal standards for the protection of the marine environment from pollution as a result of the lawmaking activities of the International Maritime Organization, Ocean Management, 1(4), 19-22 (2019)

9. O.A. Khotko, The legal nature of the environmental safety of transport activities, Legal state: theory and practice, 1(51), 174-182 (2018)

10. A.O. Mursaliev, Multilateral international legal mechanisms for the Caspian environmental protection, Zakon i pravo, 1, 128-131 (2021)

11. S.A. Vasiliev, Problems of ensuring the environmental safety of commercial sailing, Ocean management, 1(10), 18-22 (2021) 